\title{
A phase-locked loop using ESO-based loop filter for grid-connected converter: performance analysis
}

\author{
Baoling Guo ${ }^{1} \cdot$ Seddik Bacha ${ }^{2} \cdot$ Mazen Alamir $^{3}$. Julien Pouget ${ }^{1}$
}

Received: 11 October 2020 / Revised: 28 November 2020 / Accepted: 1 December 2020 / Published online: 26 March 2021

(c) The Author(s) 2021

\begin{abstract}
An extended state observer (ESO)-based loop filter is designed for the phase-locked loop (PLL) involved in a disturbed gridconnected converter ( $\mathrm{GcC}$ ). This ESO-based design enhances the performances and robustness of the PLL, and, therefore, improves control performances of the disturbed GcCs. Besides, the ESO-based LF can be applied to PLLs with extra filters for abnormal grid conditions. The unbalanced grid is particularly taken into account for the performance analysis. A tuning approach based on the well-designed PI controller is discussed, which results in a fair comparison with conventional PItype PLLs. The frequency domain properties are quantitatively analysed with respect to the control stability and the noises rejection. The frequency domain analysis and simulation results suggest that the performances of the generated ESO-based controllers are comparable to those of the PI control at low frequency, while have better ability to attenuate high-frequency measurement noises. The phase margin decreases slightly, but remains acceptable. Finally, experimental tests are conducted with a hybrid power hardware-in-the-loop benchmark, in which balanced/unbalanced cases are both explored. The obtained results prove the effectiveness of ESO-based PLLs when applied to the disturbed GcC.
\end{abstract}

Keywords Grid-connected converters · Grid disturbances · Phase-locked loop · Loop filter · Extended state observer · Tuning approach $\cdot$ Stability analysis $\cdot$ Phase margin $\cdot$ Noises attenuation $\cdot$ Power hardware-in-the-loop (PHIL) test

\section{Introduction}

Grid-connected converters ( $\mathrm{GcCs}$ ) have various applications such as grid-integrated renewable energy generation systems [1], active power filters [2], uninterruptible power supplies

Baoling Guo

baoling.guo@hevs.ch

Seddik Bacha

seddik.bacha@g2elab.grenoble-inp.fr

Mazen Alamir

mazen.alamir@gipsa-lab.grenoble-inp.fr

Julien Pouget

julien.pouget@hevs.ch

1 School of Engineering, (HES-SO) University of Applied Sciences and Arts of Western Switzerland, Sion, 1950 Valais, Switzerland

2 Institute of Engineering Grenoble, University Grenoble Alpes, CNRS, G2Elab, 38000 Grenoble, France

3 Institute of Engineering Grenoble, University Grenoble Alpes, CNRS, GIPSA-Lab, 38400 Saint Martin D'Hères, France
[3], etc. The phase-locked loop (PLL) is widely used for the $\mathrm{GcCs}$ to obtain the information of the voltage phase and the grid frequency [4, 5]. A PLL is a closed-loop feedback control system, which consists of three basic elements: phase detector, loop filter (LF), and voltage-controlled oscillator [5]. The LF is used to suppress disturbances inside the PLL control loop. The tracking characteristics, response dynamics, and stability properties of the PLL are also mainly determined by the LF [5]. The PLLs commonly use a PI controller as the LF [4-7]. However, the PLL control systems involve various disturbances such as phase jumps, frequency deviations, voltage magnitude variations, and nonlinear dynamics [6-10]. The PLL systems may loose its synchronization after a sudden large disturbance $[11,12]$.

Large efforts are devoted to enhancing the steady-state performance and the quality of the transient of conventional PLLs. The author of [4] reviews various types of LFs including Type-1, quasi-Type-1, quasi-Type-2, and Type-3, which are applied for particular purposes. Moreover, the grid voltage measurements involve switching noises and ripples, and sensor noises $[13,14]$. Under such circumstances, the expected results of PLL would be not reliable. Some works 
attempt to use the prefilter before its input or add the lowpass filler inside the control loop to address such issues [13, 14]. Furthermore, some adaptive LF-based PLLs are proposed such as the adaptive frequency estimation loop design [15] and the adaptive loop gain mechanism [16]. However, the strategy proposed in [15] has a high requirement on the PLL control input. The adaptive loop gain may cause oscillations problems [16].

The extended state observer (ESO) is a partial-modelbased observer, which is first defined in the frame of active disturbance rejection control (ADRC) [17]. Although it is originally proposed in a nonlinear structure [17], a linear ESO has been increasingly used as it is easier to design and simpler to implement [18]. The ESO-based control treats all disturbed factors affecting the plant such as system nonlinearities, uncertainties, and external disturbances as a generalized disturbance [17]. The generalized disturbance is then observed by ESO and compensated into the closedloop dynamics. Such structure enables excellent capabilities in dealing with disturbances or uncertainties [19]. Moreover, the previous work indicates that the ESO-based control achieves better ability to attenuate high-frequency noises [20]. This work attempts to exploit the ESO's potential advantages to achieve an efficient and robust PLL system, and therefore, improve control performances of the disturbed GcCs.

The previous works commonly compare the ESO-based controller with PI controllers to verify its effectiveness [21-23]. The critical point is to determine under which conditions, the comparison might be viewed as fair. The conventional PI is a single-degree-of-freedom controller [24]. The proportional term and integral term are selected by considering the stability conditions and the quality of the transient [7]. An ESO-based controller, however, is a two-degree-of-freedom (2DOF) controller [25]. The controller bandwidth and the observer bandwidth can be adjusted separately. The observer bandwidth is mainly limited by sensor sensitivity [26]. In [8], a linear ESO is used to enhance control dynamics of the PLL. The natural frequency of PI closed-loop control system and the control bandwidth of ESO-based control are tuned to be the same for the comparison study [8]. However, such comparison is not really fair [20]. The authors of [20] formulate the linear ADRC by a feedback compensator with a prefilter. The compensator can be generated with a PI controller filtered by a low-pass filter [20]. The tuning approach discussed in [20], which is based on the well-tuned parameters of PI controller, is considered in this work. The feedback compensator is tuned to have almost the same gain at cross frequency with the PI control system, which results in a relatively fair comparison between these two different types of controllers.
This work can be viewed as an extension of our previous work [8], which particularly deals with the following three aspects:

1. First, this work introduces a different tuning approach. The parameters of ESO-based controller are generated based on the well-designed PI controller, which results in a fair comparison with conventional PI-type PLLs.

2. Then, the frequency domain properties are quantitatively analysed with respect to the control stabilities and the noises rejection.

3. Finally, more complete Matlab/Simulink simulation and power hardware-in-the-loop (PHIL)-based experimental results are provided to analyse the performances of the ESO-based PLLs and check its applicability to the GcCs.

The paper is organized as follows: the ESO-based PLLs are briefly reviewed in Sect. 2 . The tuning approach and the parameter selection guidelines are presented in Sect. 3. The frequency domain analysis is followed in Sect. 4. Simulation studies are conducted before the experimental validation in Sect. 5. The PHIL tests and experimental results are presented in Sect. 6. Conclusions are provided in Sect. 7.

\section{ESO-based SRF-PLL design}

An ESO-based synchronous reference frame phase-locked loop (SRF-PLL) is shown in Fig. 1 . In the figure, $v_{a}, v_{b}, v_{c}$ are the three-phase grid voltages, $v_{d e}, v_{q e}$ are the voltages in a rotating $d q$ reference frame, $V_{\mathrm{m}}$ is the magnitude of grid voltage, $\omega_{\mathrm{g}}$ is the grid nominal angular frequency, $\hat{\omega}$ is the estimated grid angular frequency, $\Delta \hat{\omega}$ is the estimated angular frequency deviation, $\theta$ is the actual phase angle of grid voltage, and $\hat{\theta}$ is the estimated phase angle of grid voltage. Moreover, the general design rules for an SRF-PLL have been highlighted in [10], which are also followed in this work.

The proposed ESO-based LF can be incorporated into SRF-PLLs equipped with additional filters for abnormal grid conditions, whose filters are placed before its input [27] or inside the control loop [28]. Two representative designs under unbalanced grid, decoupled PLL (DPLL) [27] and moving average filter (MAF)-PLL [28], as illustrated in Figs. 2 and 3, are particularly studied for the performance analysis. The design details of DPLL/MAF-PLL can be found in previous works [27, 28]. 
Fig. 1 Schematic diagram of ESO-based SRF-PLL. $P D$ phase detector, $L F$ loop filter, $V C O$ voltage-controlled oscillator

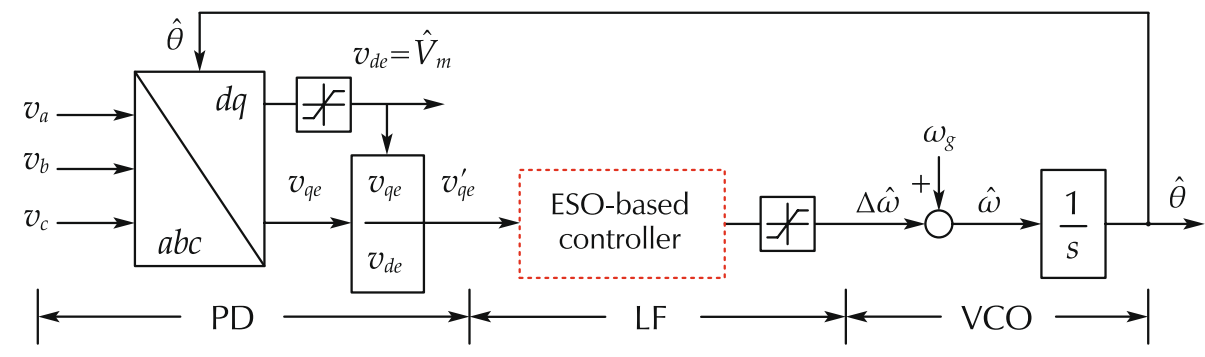

Fig. 2 Schematic diagram of ESO-based DPLL, with low-pass filter (LPF), $v_{\alpha}, v_{\beta}$ the voltages in a $\alpha \beta$ rotating reference frame, $T_{d q^{+}}$and $T_{d q^{-}}$are the positive and negative sequences transforming matrices, respectively, superscript ${ }^{+} /^{-}$represent the positive and negative sequences components, respectively, and the upper index " ${ }^{-}$, indicates variables after filters

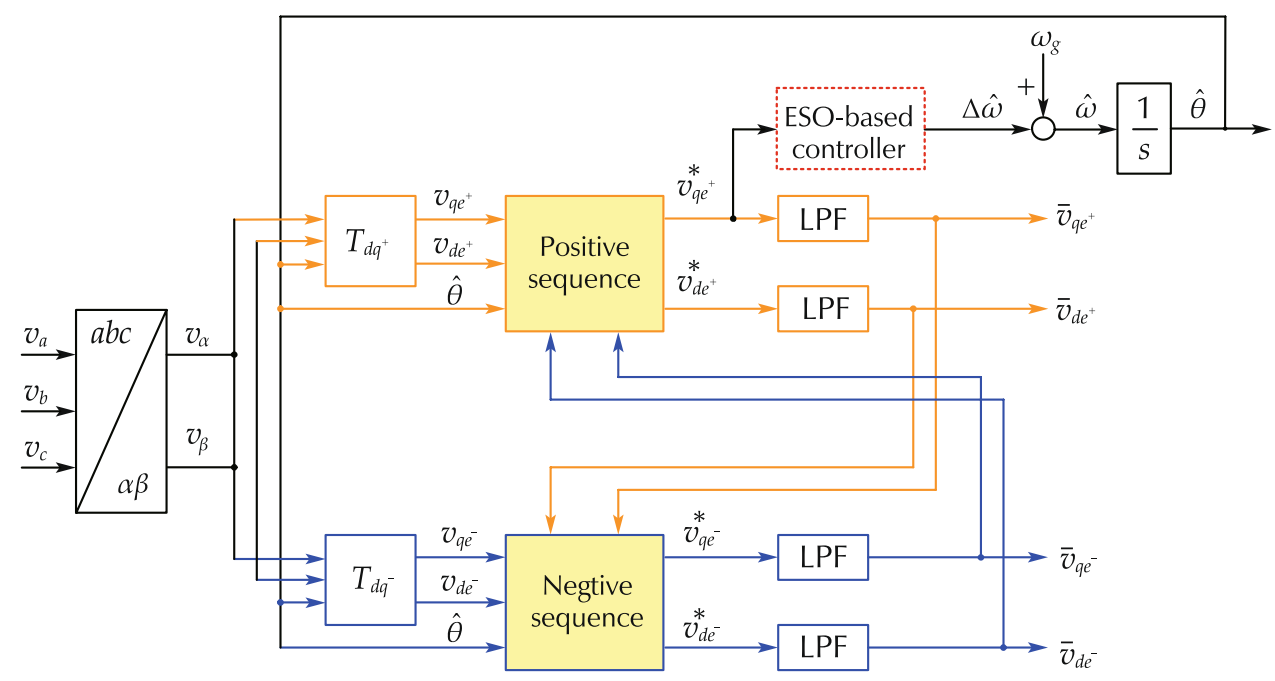

Fig. 3 Schematic diagram of ESO-based MAF-PLL, where the upper index '-, indicates variables after filters

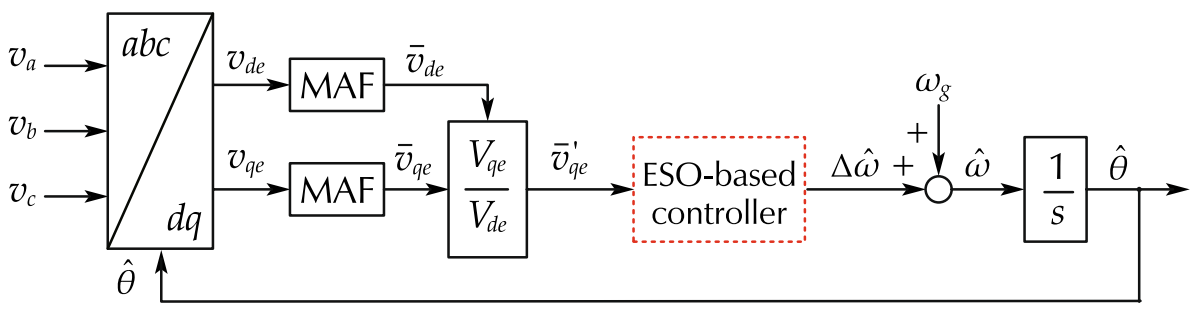

\subsection{SRF-PLL modelling}

The modelling of SRF-PLL is briefly reviewed (see Fig. 1). The grid voltages are generally represented by

$$
\left[\begin{array}{l}
v_{a} \\
v_{b} \\
v_{c}
\end{array}\right]=V_{m}\left[\begin{array}{c}
\cos \theta \\
\cos \left(\theta-\frac{2 \pi}{3}\right) \\
\cos \left(\theta+\frac{2 \pi}{3}\right)
\end{array}\right],
$$

where $\theta$ is the phase angle and $V_{m}$ is the voltage magnitude. The $v_{d q e}=\left[v_{d e}, v_{q e}\right]^{\mathrm{T}}$ under a synchronous $d q$ frame can be transformed by:

$\left[\begin{array}{l}v_{d e} \\ v_{q e}\end{array}\right]=V_{m}\left[\begin{array}{c}\cos (\hat{\theta}-\theta) \\ \sin (\hat{\theta}-\theta)\end{array}\right]=V_{m}\left[\begin{array}{c}\cos \delta \\ \sin \delta\end{array}\right]$ with the phase difference $\delta=\hat{\theta}-\theta$. For small values of $\delta$, the term $\sin \delta$ behaves linearly as follows [7]:

$v_{q e}=V_{m} \sin \delta \approx V_{m} \delta$.

As indicated by (3), the $v_{q e}$ contains the phase error information of the actual phase angle $\theta$ and the estimated phase angle $\hat{\theta}[7]$. Therefore, the phase-locked mechanism can be achieved by controlling the $q$-axis voltage $v_{q e}$ to be zero. The relation between $v_{q e}$ and $\hat{\omega}$ is derived by

$\frac{\mathrm{d} v_{q e}}{\mathrm{~d} t} \approx V_{m} \frac{\mathrm{d}(\hat{\theta}-\theta)}{\mathrm{d} t} \approx V_{m}(\hat{\omega}-\omega)$,

where $\omega=\frac{\mathrm{d} \theta}{\mathrm{d} t}$ and $\hat{\omega}=\frac{\mathrm{d} \hat{\theta}}{\mathrm{d} t}$ are the actual and estimated frequency, respectively. 


\subsection{Extended state observer}

A linearised model of ESO-based SRF-PLL control system is detailed in Fig. 4. The ESO can estimate the total disturbances and track the information of the output $y=v_{q e}^{\prime}$ simultaneously. The estimated output $\hat{x}_{1}$ is disturbance-free, with less measurement noises. The estimated disturbances $\hat{x}_{2}$ are compensated into the signal $u_{0}$. A proportional controller $k_{p}$ is employed to regulate the $q$-axis voltage. We can choose either the estimated $\hat{x}_{1}$ via an ESO or the measured output by the voltage sensor as the feedback signal, as shown in Fig. 4. If we use the estimated $\hat{x}_{1}$ to compare with the reference for the feedback control, the design is actually the same as a first-order linear ADRC PLL. We could also use the measurement as the feedback on condition that the voltage sensor has a good noise rejection ability. Otherwise, the measurement noises would be introduced into the closed-loop control system via the feedback. For the second case, the ESO is only used for observing the total disturbances. Note that the estimated $\hat{x}_{1}$ is chosen as the feedback signal to present the controller design, the tuning approach, and the forthcoming stability analysis.

A key procedure is to reformulate a practical control issue to the canonical model of cascade integrators with total disturbances [29]. Based on expression (4) and Fig. 4, the manipulation is conducted as follows:

$\frac{1}{V_{d e}} \frac{\mathrm{d} v_{q e}}{\mathrm{~d} t}=\frac{V_{m}}{V_{d e}} \frac{\mathrm{d}(\hat{\theta}-\theta)}{\mathrm{d} t}=b_{0} \Delta \hat{\omega}+d$.

A proper disturbance definition is critical to enable a highefficiency ESO [29]. Since, in the PLL, the $v_{d e}$ is the realtime estimation of $V_{m}$, the control gain $b=V_{m} / v_{d e}$ approximates 1 . Therefore, the estimation of control gain is set to $b_{0}=1$. Besides, the nominal grid frequency $\omega_{g}$ is feed-forwarded in the control input. Such operation helps improving the ESO estimation's efficiency [29]. Finally, the total disturbance $d$ is formulated by

$d=\left(b-b_{0}\right) \Delta \hat{\omega}+\left(\omega_{g}-\omega\right)+\delta_{w}$, where $\left(b-b_{0}\right) \Delta \hat{\omega}$ is due to the small mismatch between $b$ and $b_{0}, \omega_{g}-\omega$ is the grid frequency variations, and $\delta_{w}$ represents the extra unknown input disturbances induced by phase jumps, time-varying parameters, nonlinear dynamics, etc.

In the sequel, the following definitions are used: $\Delta \hat{\omega}$ is the control input $u, v_{q e}^{*}$ is the reference $r, v_{q e}^{\prime}$ is the output $y$, which is defined as a state variable by $x_{1}=v_{q e}^{\prime}, d$ is treated as an extended state variable, and expressed by $x_{2}=d$, and its time derivative is given by $\dot{x}_{2}=h$ [8]. Now, the state space model is built as follows:

$\left[\begin{array}{l}\dot{x_{1}} \\ \dot{x_{2}}\end{array}\right]=\left[\begin{array}{ll}0 & 1 \\ 0 & 0\end{array}\right]\left[\begin{array}{l}x_{1} \\ x_{2}\end{array}\right]+\left[\begin{array}{c}b_{0} \\ 0\end{array}\right] u+\left[\begin{array}{l}0 \\ 1\end{array}\right] h$.

Based on (7), the ESO can be formulated as follows:

$\left[\begin{array}{l}\dot{\hat{x}}_{1} \\ \hat{x}_{2}\end{array}\right]=\left[\begin{array}{ll}0 & 1 \\ 0 & 0\end{array}\right]\left[\begin{array}{l}\hat{x}_{1} \\ \hat{x}_{2}\end{array}\right]+\left[\begin{array}{c}b_{0} \\ 0\end{array}\right] u+\left[\begin{array}{l}\beta_{1} \\ \beta_{2}\end{array}\right]\left[x_{1}-\hat{x}_{1}\right]$.

By subtracting (8) from (7), the error dynamics are defined by:

$\left[\begin{array}{l}\dot{e_{1}} \\ \dot{e_{2}}\end{array}\right]=\left[\begin{array}{ll}-\beta_{1} & 1 \\ -\beta_{2} & 0\end{array}\right]\left[\begin{array}{l}e_{1} \\ e_{2}\end{array}\right]+\left[\begin{array}{l}0 \\ 1\end{array}\right] h$,

where $e_{1}=x_{1}-\hat{x}_{1}$ is the state estimation error, and $e_{2}=x_{2}-\hat{x}_{2}$ is the disturbances estimation error.

The positive gains of ESO are given by $\beta_{1}=\xi \omega_{o}$ and $\beta_{2}=\omega_{o}^{2}$, the coefficient $\xi=2$ is commonly chosen for the Hurwitz stable consideration [18], and the $\omega_{o}$ is referred to as the bandwidth of ESO. The coefficient $\xi$ is introduced to ensure the control stability for the PLL with in-loop filter [28]. Regarding the classical definition in [18], the $\omega_{o}$ cannot be called the bandwidth of ESO for $\xi \neq 2$. Then, the $\omega_{0}$ can be viewed as a general parameter to be tuned.

\subsection{Control law formulation}

Based on Fig. 4, the control law is represented by
Fig. 4 Linearised control diagram of ESO-based SRF-PLL, $\beta_{1}$ and $\beta_{2}$ are the positive gains of ESO, $\delta_{w}$ is the unknown input disturbances, and $b_{0}$ is the estimation of control gain

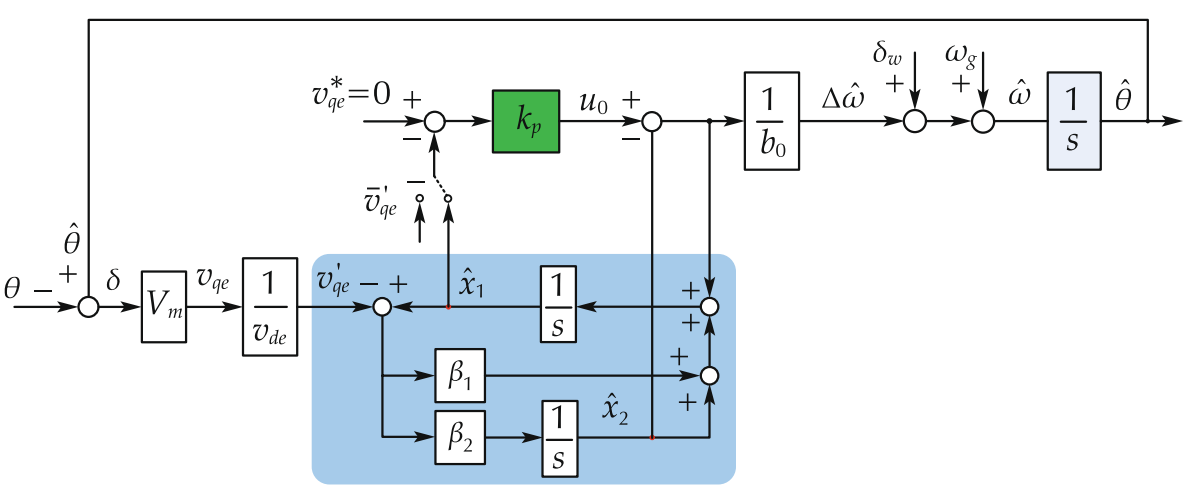


$\Delta \hat{\omega}=\frac{k_{p}\left(v_{q e}^{*}-\hat{x}_{1}\right)-\hat{x}_{2}}{b_{0}}$.

The original plant model is reduced to be an integrator within the ESO's bandwidth $[30,31]$. Therefore, we can approximate the closed-loop transfer function by

$H_{\mathrm{c}}(s) \approx \frac{k_{p} \frac{1}{s}}{1+k_{p} \frac{1}{s}}=\frac{1}{1+\frac{s}{k_{p}}}$

with the closed-loop control bandwidth $\omega_{c} \approx k_{p}$.

\section{Tuning approach}

The previous research [20] has proved that, under some conditions, a first-order ESO-based controller can stabilize the plant if it can be stabilized by a PI controller. Therefore, we can configure an ESO-based controller based on a welltuned PI controller. More importantly, such design enables a relatively fair comparison between the PI and the ESO-based controller.

\subsection{Formulation of 2DOF block diagram}

First, the transfer functions can be obtained from (5)-(10) as follows:

$\frac{u(s)}{y(s)}=-\frac{\left(\xi \omega_{o} \omega_{c}+\omega_{o}^{2}\right) s+\omega_{o}^{2} \omega_{c}}{b_{0} s\left(s+\xi \omega_{o}+\omega_{c}\right)}$

$\frac{u(s)}{r(s)}=\frac{\left(s^{2}+\xi \omega_{o} s+\omega_{o}^{2}\right) \omega_{c}}{b_{0} s\left(s+\xi \omega_{o}+\omega_{c}\right)}$

where $r(s), u(s)$, and $y(s)$ are the Laplace transforms of $r=v_{q e}^{*}, u=\Delta \hat{\omega}$, and $y=v_{q e}^{\prime}$, respectively. By introducing the following notations:

$C(s)=\frac{\left(\xi \omega_{o} \omega_{c}+\omega_{o}^{2}\right) s+\omega_{o}^{2} \omega_{c}}{b_{0} s\left(s+\xi \omega_{o}+\omega_{c}\right)}$,

$H(s)=\frac{\left(s^{2}+\xi \omega_{o} s+\omega_{o}^{2}\right) \omega_{c}}{\left(\xi \omega_{o} \omega_{c}+\omega_{o}^{2}\right) s+\omega_{o}^{2} \omega_{c}}$,

the ESO-based controller is formulated to a 2DOF closedloop system as shown in Fig. 5a. Now, we have a similar structure as a classical PI control system Fig. 5b except the prefilter. The authors of [32] indicate that the prefilter does not affect the feedback properties.

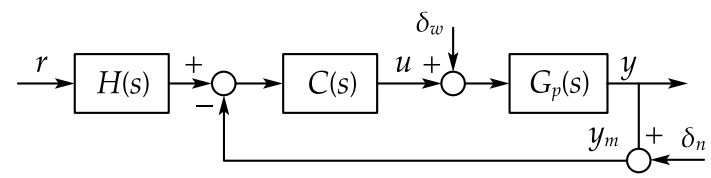

(a)

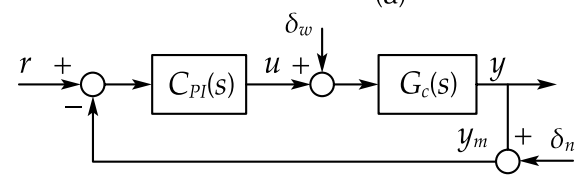

(b)

Fig. 5 a ESO-based control 2DOF diagram. b Classical PI closedloop control diagram. $\delta_{w}$ : the unknown input disturbances. $\delta_{n}$ : measurement noises

\subsection{Updating ESO-based controller with PI controller}

The feedback compensator $C(s)$ can be updated with a PI controller filtered by a low-pass filter as follows:

$C(s)=C_{P I}(s) \frac{\xi \omega_{o}+\omega_{c}}{s+\xi \omega_{o}+\omega_{c}}$.

The well-tuned PI controller is expressed by

$C_{P I}(s)=K_{P}+\frac{K_{I}}{s}$

with

$K_{P}=\frac{\xi \omega_{o} \omega_{c}+\omega_{o}^{2}}{N b_{0}\left(\xi \omega_{o}+\omega_{c}\right)}, \quad K_{I}=\frac{\omega_{o}^{2} \omega_{c}}{N b_{0}\left(\xi \omega_{o}+\omega_{c}\right)}$,

where the gain correction factor $N$ is introduced to ensure that the ESO-based control has the similar behaviour with PI control in low frequency. By solving Eq. (18), we have

$\omega_{c}=\frac{K_{I} \omega_{o}}{K_{P} \omega_{o}-\xi K_{I}}$.

Note that the denominator $\left(K_{P} \omega_{o}-2 K_{I}\right)$ in Eq. (19) must be positive to satisfy the stability condition, leading to the following expression:

$\omega_{o}>\xi K_{I} / K_{P}$.

Once the parameters $\xi$ and $\omega_{o}$ are determined, the gain correction factor $N$ can be obtained with Eq. (18). As shown in Fig. 6, the transfer functions (14) and (16) present the same bode behaviours by introducing the gain correction factor. The gain correction factor $N$ is introduced to ensure that the ESO-based control has the similar behaviour with PI control in low frequency. Otherwise, there would exist a constant gain difference between them. The parameters tuning guidelines will be detailed as follows. 

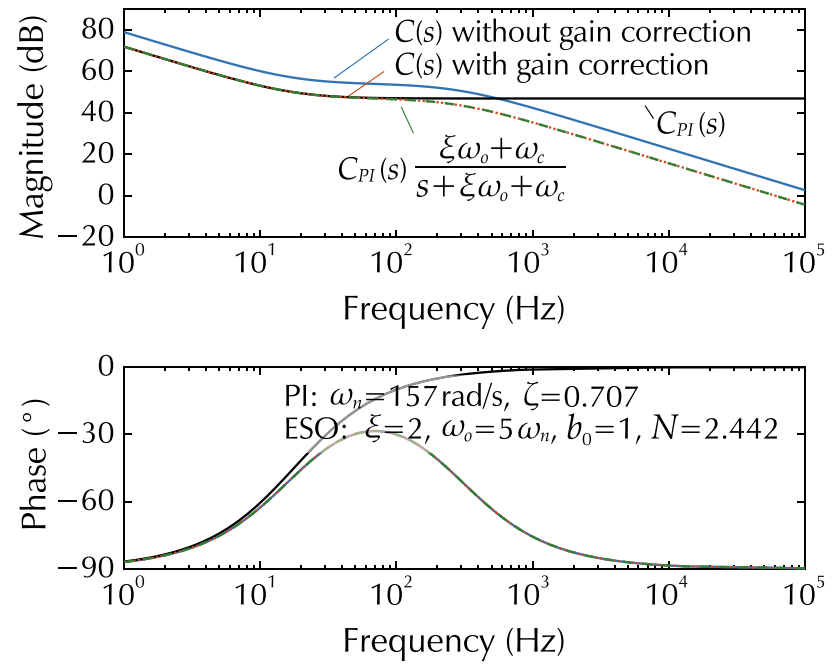

Fig. 6 Bode diagram of $C(s), C_{P I}(s)$, and $C_{P I}(s) \frac{\xi \omega_{o}+\omega_{c}}{s+\xi \omega_{o}+\omega_{c}}$

\subsection{Tuning guidelines}

Now, we can generate the ESO-based controller with the PI controller. Based on the above discussions, the tuning guidelines are summarized as follow:

- First, we choose the well-tuned PI parameters that have been validated in previous works.

- Regarding the parameter $b_{0}$, since, in the PLL, the $v_{d e}$ is the real-time estimation of $V_{m}$, the control gain $b=V_{m} / v_{d e}$ approximates 1 . It is reasonable to set the estimation of control gain to $b_{0}=1$.

- The coefficient $\xi=2$ is commonly chosen for the Hurwitz stable consideration [18]. Starting from $\omega_{o}>\xi K_{I} / K_{P}$, we increase $\omega_{o}$ for Eqs. (16)-(19) until reaching noise limitations [26].

- Then, the parameters $N$ and $\omega_{c}$ are the solutions of (18)(19), respectively.

- Note that, for a PLL with in-loop filter, the coefficient $\xi$ has to be corrected to ensure the control stability.

- Finally, it is mandatory to validate the applied parameters of ESO-based controller in the physical tests.

The parameters of the chosen PI controllers for PLLs are given in Table 1 . The parameters $K_{P}$ and $K_{I}$ for SRF-PLL are selected based on the design method described in [7]. Besides,

Table 1 Well-tuned PI parameters for different types of PLLs

\begin{tabular}{ll}
\hline SRF-PLL & $K_{P}=222, K_{I}=24649$ \\
\hline DPLL [27] & $k_{\mathrm{f}}=0.707, K_{\mathrm{DP}}=222, K_{\mathrm{DI}}=24649$ \\
MAF-PLL [28] & $T_{\mathrm{w}}=0.01 s, K_{\mathrm{MP}}=83, K_{\mathrm{MI}}=2893$ \\
\hline
\end{tabular}

the well-designed parameters for the DPLL and the MAF-PLL provided in $[27,28]$ are considered, as well.

\section{Frequency domain analysis}

The stability index is a crucial factor for evaluating the quality of a controller [10, 20, 33]. An ESO-based PLL is described in [8]; however, no detailed stabilities analyses are provided. The stability properties are, therefore, quantitatively analysed in this work. Besides, the high-frequency noise rejection ability and the closed-loop performance are analysed, as well. The noise suppression effect of ESO itself is also presented. Note that the tuning guidelines discussed in Sect. 3 will be followed in the forthcoming analysis.

\subsection{Stabilities analysis}

The stability of the prefilter $H(s)(15)$ is guaranteed, as all coefficients of its denominator are positive [33]. Indeed, the prefilter does not affect the feedback properties [32]. Therefore, the closed-loop stability can be determined by the forward gain transfer function, which is given by

$$
\begin{aligned}
L(s) & =C(s) G_{p}(s) \\
& =\frac{\xi \omega_{o}+\omega_{c}}{s+\xi \omega_{o}+\omega_{c}} C_{P I}(s) G_{p}(s),
\end{aligned}
$$

where the plant model is $G_{p}(s)=b / s$, and $b=V_{m} / v_{d e}$. The stability will be analysed with respect to the observer bandwidth $\omega_{o}$, the robustness for plant model uncertainness, and the effects of extra filters.

The bode diagram of $L(s)=C(s) G_{p}(s)$ is shown in Fig. 7, with $\omega_{o} \in\left\{3 \omega_{n}, 5 \omega_{n}, 7 \omega_{n}\right\} \mathrm{rad} / \mathrm{s}$. The remaining parameters
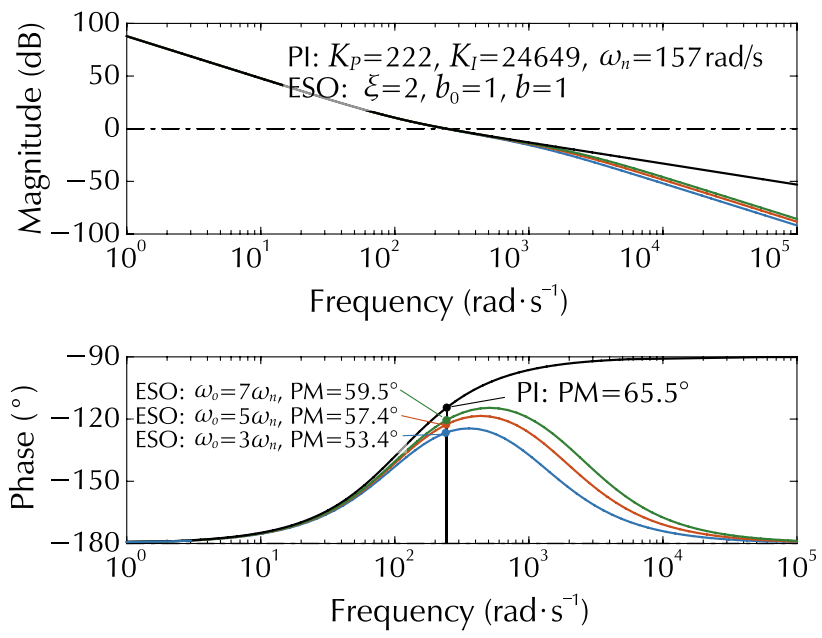

Fig. 7 Bode plots of $L(s)$ for $\omega_{o} \in\left\{3 \omega_{n}, 5 \omega_{n}, 7 \omega_{n}\right\}$ 
are selected by following the tuning guidelines summarized in Sect. 3. Figure 7 shows that, in low-frequency range, the ESO-based control behaves closely to the bode feature of the PI controller. Compared to the PI controller, however, its stability margin decreases due to the effect of low-pass filter. The phase margin $(\mathrm{PM})$ within a range of $30^{\circ} \sim 60^{\circ}$ is commonly recommended regarding the control stability [28]. Therefore, the phase margin remains acceptable $\left(\mathrm{PM}>50^{\circ}\right)$. It can also be observed that the PM increases with larger $\omega_{o}$, which can therefore enhance the control stabilities. However, the $\omega_{o}$ cannot be too large, because it is limited by sensor noises and practical considerations. The parameter $\omega_{0}$ must be validated in practical conditions.

The stability of the control system can be affected by the plant model discrepancies. The main uncertain parameter for the SRF-PLL is the plant gain $b$ as indicated by Eq. (22). The control robustness are therefore assessed under different values of $b$ :

$L_{b}(s)=\frac{\left(\xi \omega_{o} \omega_{c}+\omega_{o}^{2}\right) s+\omega_{o}^{2} \omega_{c}}{N b_{0} s\left(s+\xi \omega_{o}+\omega_{c}\right)} \times \frac{b}{s}$.

The control gain $b=V_{m} / v_{d e}$ approximates 1 , and its estimation is set to $b_{0}=1$. The bode plots of the loop transfer function $L_{b}(s)$ for $b \in\{0.5,1.0,2.0, N, 3.0\}$ are provided in Fig. 8. The phase margin decreases when the $N b_{0}$ is far from the real value of $b$. Though the phase margins are always acceptable.

Now, the stabilities of ESO-based PLLs with extra fillers are discussed. Regarding the DPLL, the prefilter has no direct effect on the control stability [27, 32]. However, the stability of the ESO-based MAF-PLL could be affected, because a Moving Average Filter (MAF) is placed inside the control loop (see Fig. 3). The parameters have to be corrected; otherwise, the oscillation problems would occur in
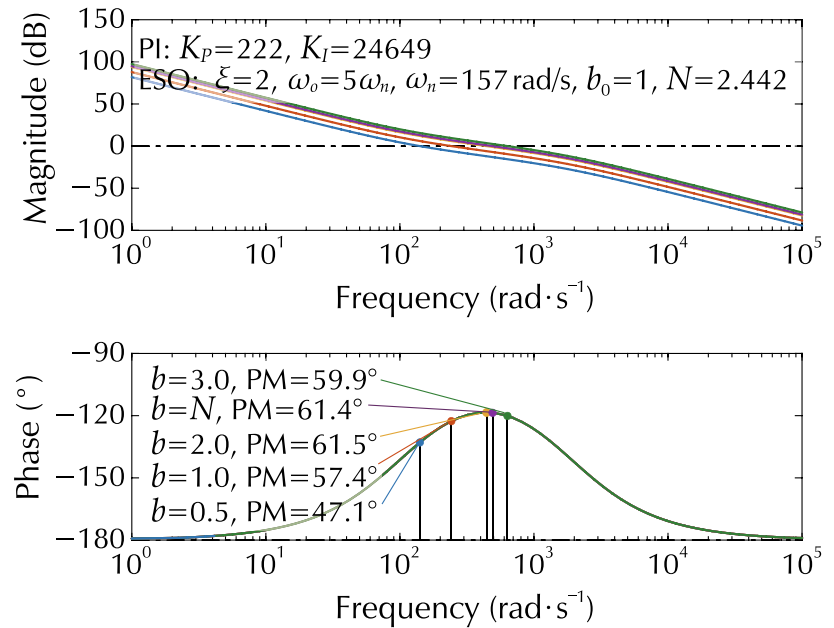

Fig. 8 Bode plots of $L_{b}(s)$ for $b \in\{0.5,1.0,2.0, N, 3.0\}$ the practical tests. The loop gain transfer function is modified as follows:

$L_{\mathrm{M}}(s)=M(s) C(s) G_{p}(s)$.

The transfer function of the MAF is approximated by [28]

$M(s) \approx \frac{1}{\frac{T_{\mathrm{w}}}{2} s+1}$

with the parameter $T_{\mathrm{w}}=0.01 \mathrm{~s}$ [28].

The bode plots of $L_{\mathrm{M}}(s)$ for different $\omega_{o}$ and $\xi$ are, respectively, shown in Figs. 9 and 10. We use the following settings: $\omega_{o} \in\left\{3 \omega_{n}, 5 \omega_{n}, 7 \omega_{n}\right\} \mathrm{rad} / \mathrm{s}, \xi=2$ for Fig. 9 and $\omega_{o}=5 \omega_{n} \mathrm{rad} / \mathrm{s}, \xi \in\{2,3,4\}$ for Fig. 10. It can be seen that the PM and the gain margin (GM) decrease much due to the effect of the MAF. The PM and GM increase with a larger
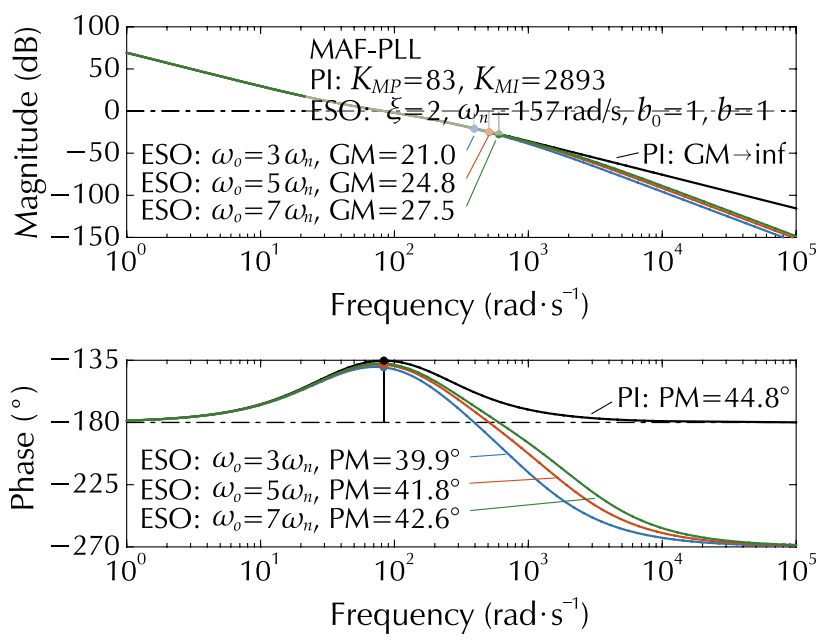

Fig. 9 Bode plots of $L_{\mathrm{M}}(s)$ for $\omega_{o} \in\left\{3 \omega_{n}, 5 \omega_{n}, 7 \omega_{n}\right\}$
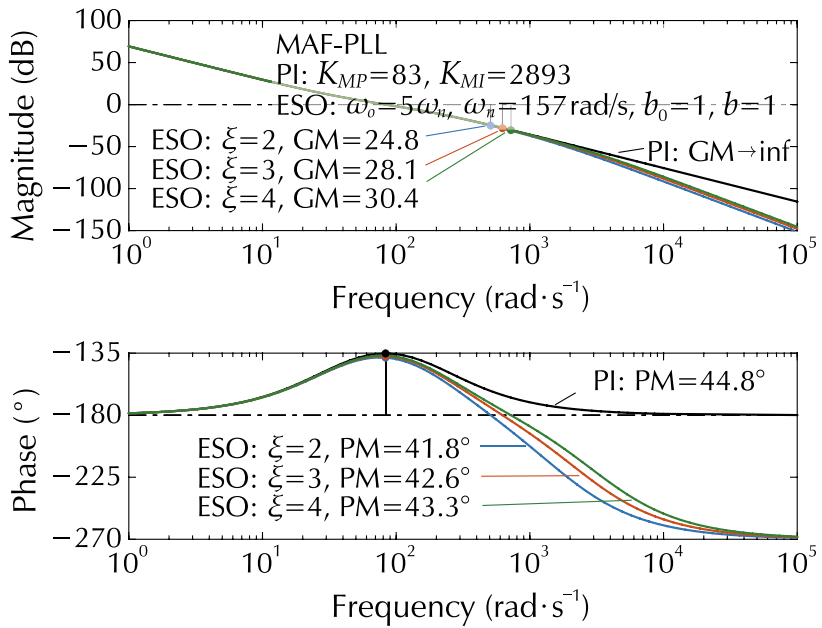

Fig. 10 Bode plots of $L_{\mathrm{M}}(s)$ for coefficient $\xi \in\{2,3,4\}$ 
$\omega_{o}$. However, the $\omega_{o}$ is limited by sensor noises. The PM and GM can be enhanced using larger $\xi$. While too large $\xi$ enables slow dynamics response [18]. Finally, the coefficient $\xi=4$, $\omega_{o}=5 \omega_{n}$ is chosen for its application into the MAF-PLL.

\subsection{Noises rejection analysis}

As illustrated in Fig. 5, the measurement noises rejection ability is determined by the transfer function as follows:

$$
\begin{aligned}
G_{n}(s) & =\frac{y(s)}{\delta_{n}(s)} \\
& =\frac{C(s) G_{p}(s)}{1+C(s) G_{p}(s)} \\
& =\frac{C_{P I}(s) G_{p}(s)}{1+C(s) G_{p}(s)} \frac{\xi \omega_{o}+\omega_{c}}{s+\xi \omega_{o}+\omega_{c}},
\end{aligned}
$$

where $y(s)$ and $\delta_{n}(s)$ are the Laplace transforms of the output $y$ and the measurement noises $\delta_{n}$, respectively.

Figure 11 shows the bode diagram of $G_{n}(s)$. The comparative results indicate that ESO-based controller behaves better to attenuate the measurements noise compared to the PI controller. As indicted in (16), that is the low-pass filter which enhances its ability to reduce high-frequency noises. Besides, the noise rejection ability decreases when the parameter $\omega_{o}$ increases.

Now, we discuss the noise attenuation effect of ESO itself. Based on Eqs. (7)-(10), the transfer function of the estimated state variable $\hat{x}_{1}$ is obtained as follows:

$\hat{x}_{1}=\frac{\xi \omega_{o} s+\omega_{o}^{2}}{s^{2}+\xi \omega_{o} s+\omega_{o}^{2}} y(s)+\frac{s}{s^{2}+\xi \omega_{o} s+\omega_{o}^{2}} u(s)$.

Then, the $\hat{x}_{1}$ resulting from the measurement noise $\delta_{n}$ and the input disturbance $\delta_{w}$ can be given by
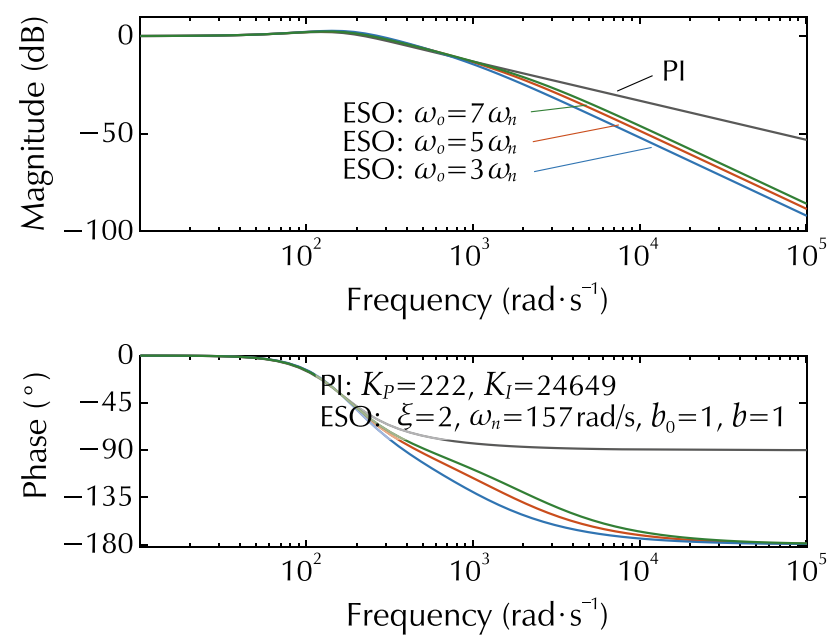

Fig. 11 Bode plots of $G_{n}(s)$ for $\omega_{o} \in\left\{3 \omega_{n}, 5 \omega_{n}, 7 \omega_{n}\right\}$ $f_{\delta_{n}}(s)=\frac{\xi \omega_{o} s+\omega_{o}^{2}}{s^{2}+\xi \omega_{o} s+\omega_{o}^{2}}$,

$$
f_{\delta_{w}}(s)=\frac{s}{s^{2}+\xi \omega_{o} s+\omega_{o}^{2}} .
$$

The bode plots of $f_{\delta_{n}}(s)$ and $f_{\delta_{w}}(s)$ are shown in Figs. 12 and 13 , respectively, with $\omega_{o} \in\left\{3 \omega_{n}, 5 \omega_{n}, 7 \omega_{n}\right\} \mathrm{rad} / \mathrm{s}$. It can be observed from Fig. 12 that the ESO performs as a low-pass filter, which can reject the high-frequency signals. Besides, the larger $\omega_{o}$ can increase the high-frequency gain. Namely, the ESO would be more sensitive to the high-frequency measurement noise when we increase the $\omega_{o}$. It can be seen from Fig. 13 that the phase lag of $\hat{x}_{1}$ is decreased with larger
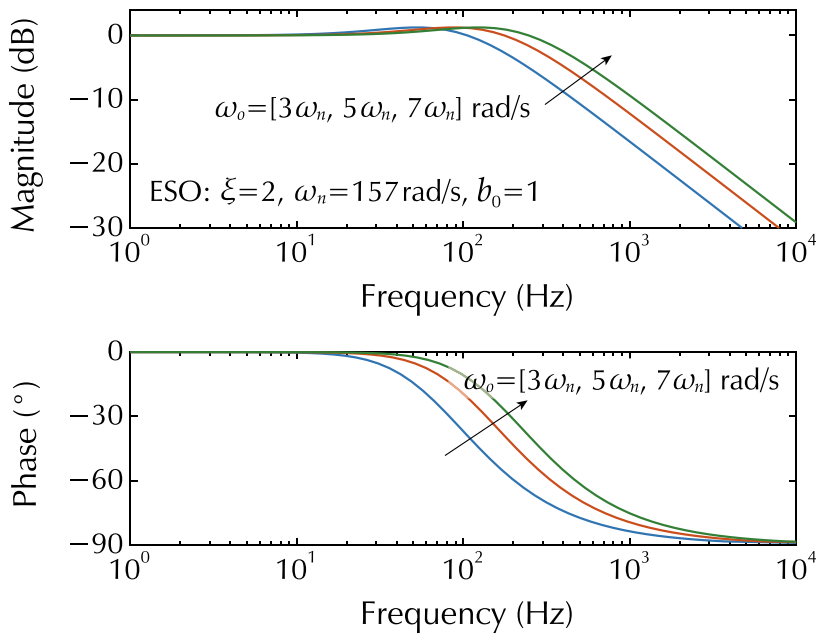

Fig. 12 Bode diagrams of the transfer function $f_{\delta_{n}}(s)$ for $\omega_{o} \in$ $\left\{3 \omega_{n}, 5 \omega_{n}, 7 \omega_{n}\right\}$
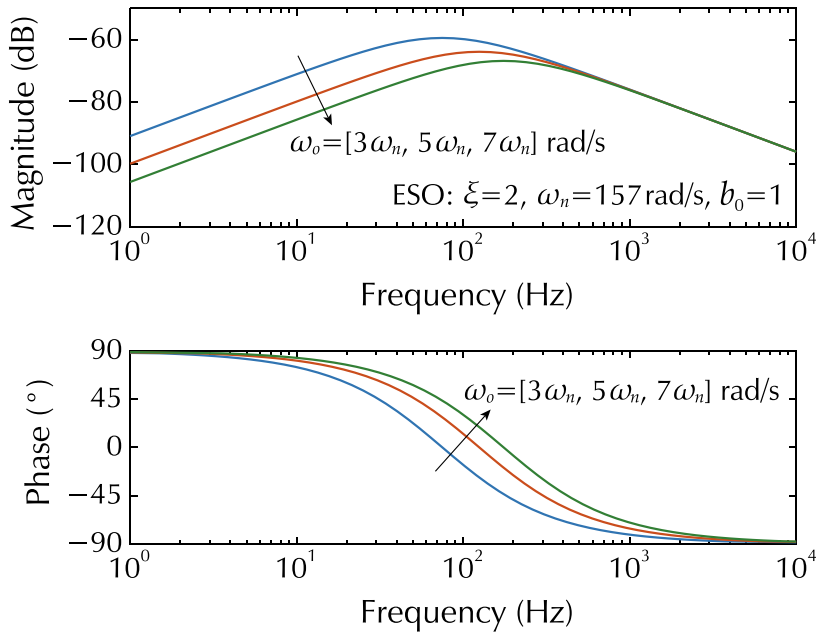

Fig. 13 Bode diagrams of the transfer function $f_{\delta_{w}}(s)$ for $\omega_{o} \in$ $\left\{3 \omega_{n}, 5 \omega_{n}, 7 \omega_{n}\right\}$ 
$\omega_{o}$; however, there is no influence on the high-frequency gain; the ESO can more efficiently attenuate the input disturbance in the low-frequency region. Consequently, there exists a trade-off between the input disturbance rejection and the measurement noise sensitivity [34].

Based on (9), the transfer function of disturbances estimation error becomes

$f_{e_{2}}(s)=\frac{e_{2}(s)}{f(s)}=\frac{s\left(s+2 \omega_{o}\right)}{\left(s+\omega_{o}\right)^{2}}$.

The bode plots of $f_{e_{2}}(s)$ are shown in Fig. 14, with $\omega_{o} \in\left\{3 \omega_{n}, 5 \omega_{n}, 7 \omega_{n}\right\} \mathrm{rad} / \mathrm{s}$. The ESO can estimate the unknown disturbance very well only when the disturbances are composed of low-frequency components [10]. The disturbance estimation errors can be reduced by increasing the $\omega_{o}$; however, the $\omega_{o}$ is limited by the noises sensitivity.

\subsection{Closed-loop performance analysis}

Based on the formulated 2DOF diagram (see Fig. 5), the closed-loop transfer function of the ESO-based PLL is represented as follows:

$G_{\mathrm{cl}}(s)=H(s) \frac{C(s) G_{p}(s)}{1+C(s) G_{p}(s)}$.

The bode plots of $G_{\mathrm{cl}}(s)$ are shown in Fig. 15. The closedloop performances of PI and ESO-based control system behave closely at the low-frequency range. It can also be noticed that there is a peak greater than $0 \mathrm{~dB}$ for the PI control system, which indeed corresponds a time-domain overshoot of the step response [20]. However, for the ESO-based control, the overshoot is attenuated due to the prefilter $\mathrm{H}(\mathrm{s})$.
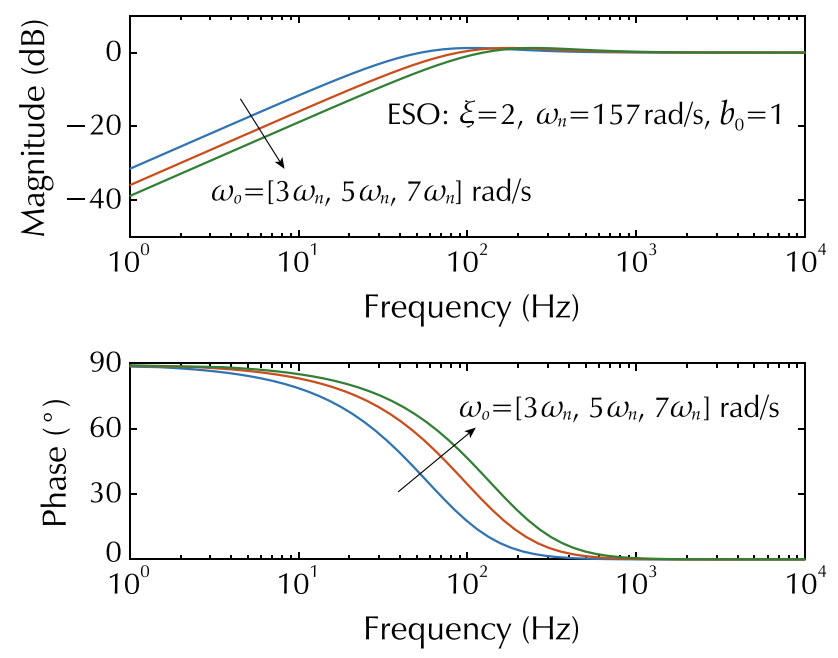

Fig. 14 Bode diagram of the transfer function $f_{e_{2}}(s)$ for $\omega_{o} \in$ $\left\{3 \omega_{n}, 5 \omega_{n}, 7 \omega_{n}\right\}$
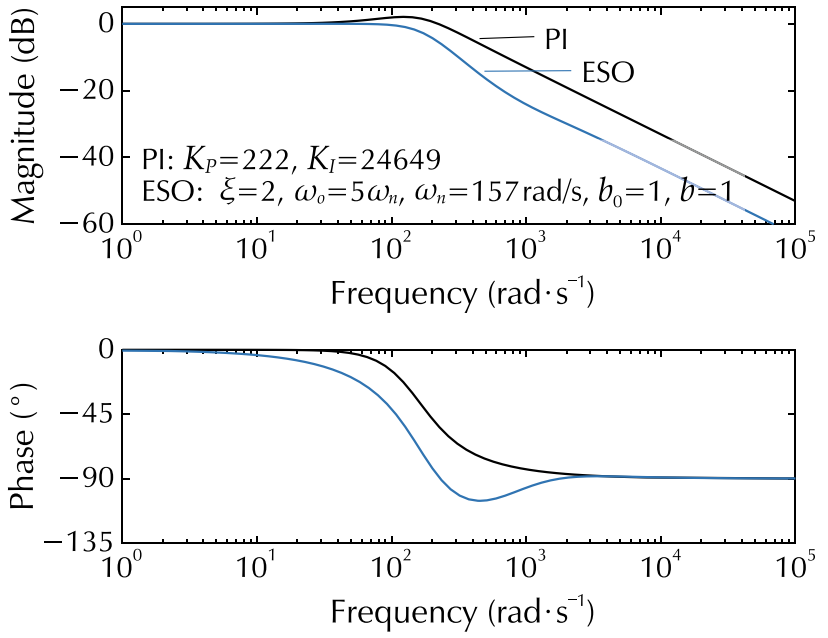

Fig. 15 Bode plot of closed-loop transfer function $G_{\mathrm{cl}}(s)$

\section{Simulation studies and results}

Simulation studies are conducted with the Matlab/Simulink. We use the solver Ode3 (Bogacki-Shampine) with a fixed step size $0.1 \mathrm{~ms}$ [8]. The balanced three-phase voltages are set to $V_{m}=179 \mathrm{~V}, f=50 \mathrm{~Hz}$. A white noise is manually added to simulate the voltage measurement noises. The ESO-based SRF-PLL/DPLL/MAF-PLL are, respectively, simulated by considering different disturbed regimes. The parameters of ESO-based PLLs are selected by following the tuning guidelines in Sect. 3; meanwhile, the control stability is taken into account, as well. The control parameters of ESO-based SRF-PLL and DPLL are set to $\omega_{o}=5 \omega_{n} \mathrm{rad} / \mathrm{s}$, $\omega_{n}=157 \mathrm{rad} / \mathrm{s}, \xi=2$, and $b_{0}=1$. Regarding the MAF-PLL, the coefficient $\xi=4$ is applied to ensure the control stability, and the remaining parameters are set to the same as those of the SRF-PLL.

The simulation results under balanced grid conditions are presented in Figs. 16 and 17. The disturbed schemes are set as follows: at $t=0.2 \mathrm{~s}$, a magnitude drop of $0.2 V_{m}$ is induced on the three-phase voltage; then, a phase jump of $+20^{\circ}$ appears at $t=0.4 \mathrm{~s}$. To avoid a too large frequency variation, a first-order transient process $1 /\left(T_{s} s+1\right)$ is added before the phase reference input, and $T_{s}=5 e^{-3} s$; at $t=0.8 \mathrm{~s}$, the frequency steps from 50 to $52 \mathrm{~Hz}$. Compared with the PI control, the ESO-based SRF-PLL achieves similar dynamic responses with respect to tracking the frequency and the phase under disturbed schemes. The estimated frequency tracks the actual frequency as quickly as the PI control, as shown in Fig. 16. Compared to the PI control, the estimated phase error comes back to zero a bit faster, though its peak values are a bit higher as shown in Fig. 17. Moreover, the ESO-based PLL performs much better to attenuate the measurements noises of the output, especially for the estimated frequency. In addition, the results of ESO-based PLLs that 
Fig. 16 Estimated frequencies of ESO-based SRF-PLL
Fig. 17 Phase tracking errors of ESO-based SRF-PLL
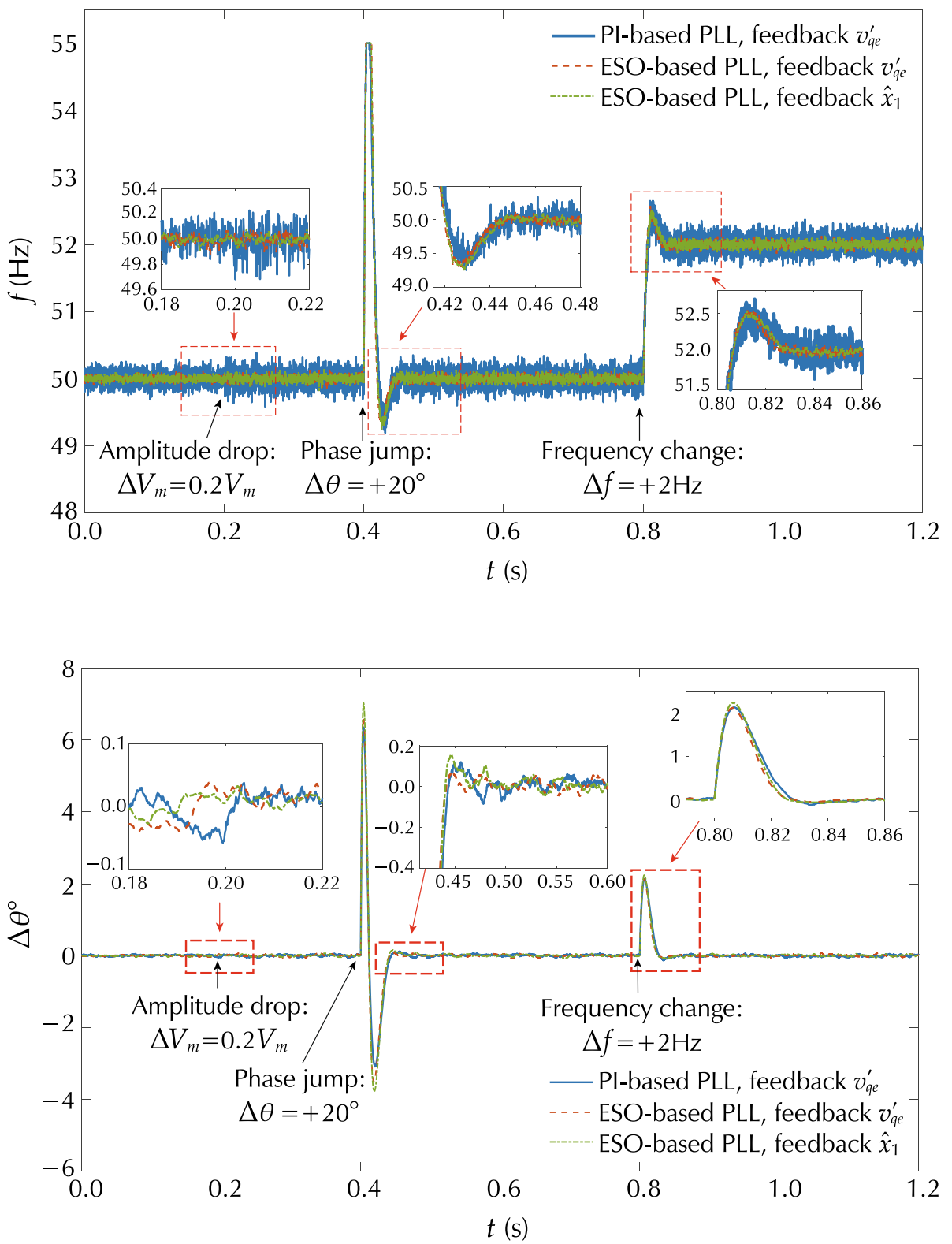

use feedback signals of $v_{q e}^{\prime}$ and $\hat{x}_{1}$ are compared, as well. If we choose $\hat{x}_{1}$ as the feedback signal for the ESO-based PLL, its measurements noise suppression ability is enhanced a bit compared to the case with feedback signal $v_{q e}^{\prime}$. The control dynamics decrease slightly, because we have chosen a large enough $\omega_{o}$.

The unbalanced case is tested to assess the effects of the extra filters on the ESO-based LF. Figures 18 and 19 show the performances of ESO-based DPLL and MAFPLL. The voltage unbalances happen at $t=0.2 \mathrm{~s}$, and the unbalanced voltages are set to $V_{a m}=V_{m}, V_{b m}=0.8 V_{m}$, $V_{c m}=0.8 V_{m}$. A phase jump of $+20^{\circ}$ is induced at $t=0.4 \mathrm{~s}$. The grid frequency varies from $50 \mathrm{~Hz}$ to $52 \mathrm{~Hz}$ at $t=0.8 \mathrm{~s}$.
The simulation results for PI controllers are also provided for the comparisons. Some conclusions are suggested by the results, as shown in Figs. 18 and 19. First, the ESO-based DPLL and MAF-PLL present almost the same dynamic responses as the corresponding PI control for tracking the information of the frequency and the phase. Then, as the MAF itself could help attenuate the high-frequency noises, consequently, the advantage of ESO-based LF when applied to the MAF-PLL is not very significant. Moreover, the DPLL performs faster response dynamics compared to the MAF-PLL. Therefore, in the following part, only the ESObased DPLL is implemented into the closed-loop control of the $\mathrm{GcC}$. 
Fig. 18 Estimated frequencies of ESO-based DPLL and MAF-PLL
Fig. 19 Phase tracking errors of ESO-based DPLL and MAFPLL
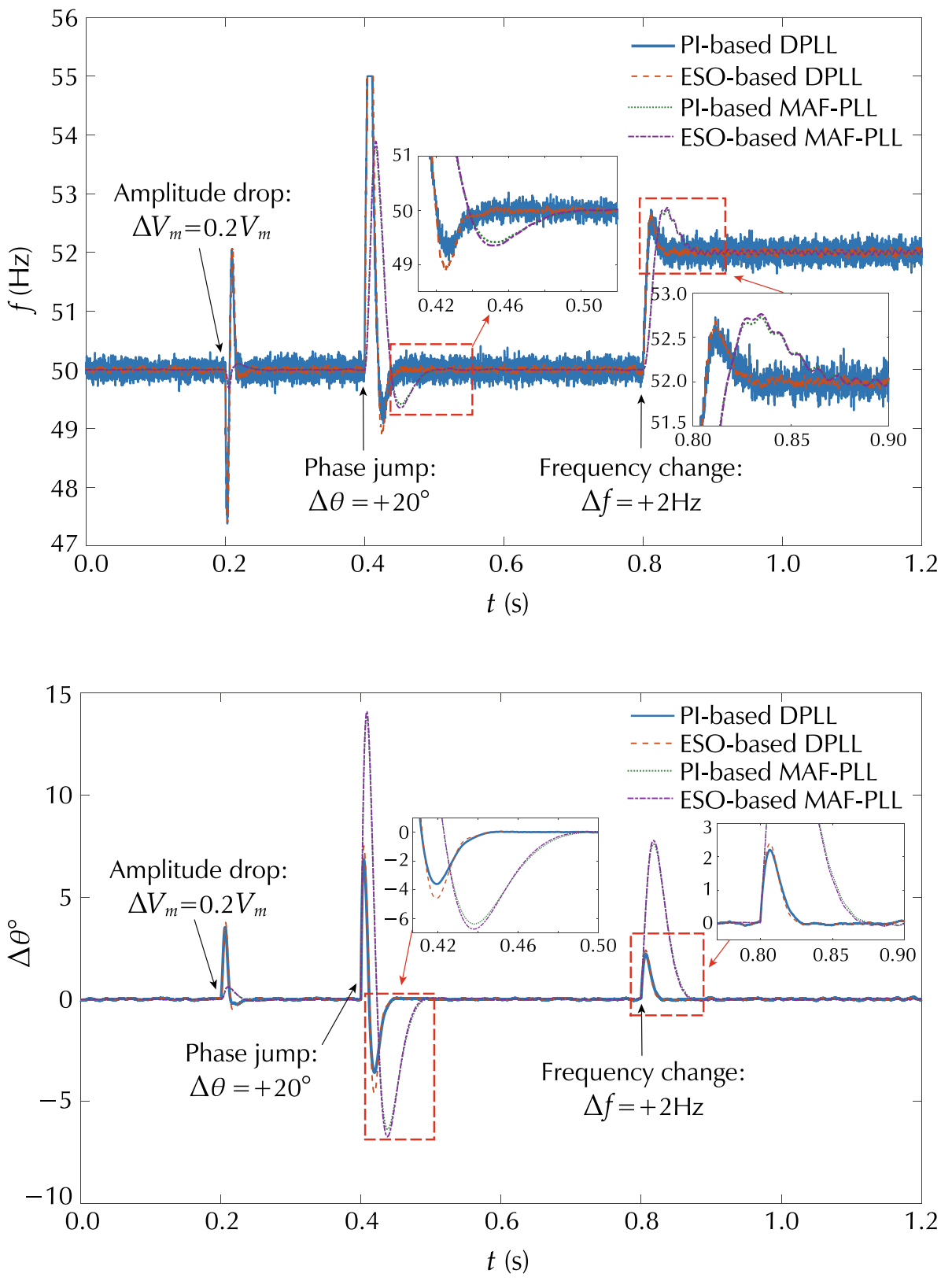

\section{Experimental tests and results}

The closed-loop control performances of $\mathrm{GcC}$ equipped with ESO-based PLL are experimentally validated in this section. Experiments are conducted in a real-time hybrid PHIL test benchmark, as schematically illustrated in Fig. 20, which consists of the three-phase grid-connected converter, the disturbed grid emulator [35], and the dSPACE hardware (DS1005) [36]. The three-phase GcC is a back-to-back Pulse Width Modulation (PWM) voltage source converter. The control signal is converted to the PWM command for the converters in real time [36]. The disturbed grid is emulated by the RT-LAB real-time digital simulator [8]. Key parameters of the testing benchmark are listed in Table 2.
The implemented control algorithms are encoded in the dSPACE modular of DS2005 board under the Matlab/ Simulink environment [36]. The control structure of gridconnected converter is illustrated in Fig. 21. In this figure, $i_{(a, b, c)}$ are the grid currents, $v_{(a, b, c)}$ are the grid voltages; $\hat{\theta}$ is the estimated phase angle of the grid voltage or the positive sequence for unbalanced case; $i_{d}^{*}$ and $i_{q}^{*}$ are $d$ - and $q$-axis grid current references; $V_{\mathrm{dc}}$ is the DC-link voltage, $C$ is the DClink capacitance; $L$ is the filter inductor, $R$ is the filter resistor; and $S_{(a, b, c)}$ are the switching states of power converters.

The control of GcCs mainly has three functions: the grid synchronization [8], the DC-link voltage control [37], and the grid current control [38]. First, the outer voltage loop maintains the constant DC-link voltage, where a PI 
Fig. 20 PHIL experimental benchmark

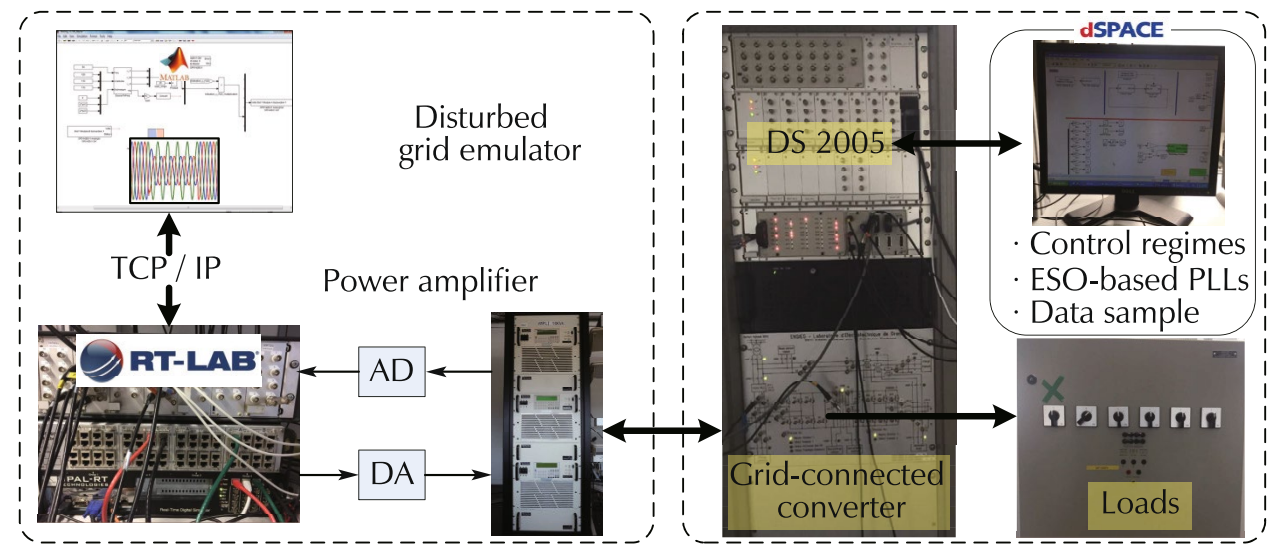

Table 2 Parameters of the experimental benchmark

\begin{tabular}{llll}
\hline Parameters & Values & Parameters & Values \\
\hline DC-link voltage & $450 \mathrm{~V}$ & DC loads & $200 \Omega$ \\
Grid voltage amp & $179 \mathrm{~V}$ & Grid filter resistor & $0.17 \Omega$ \\
Grid frequency & $50 \mathrm{~Hz}$ & Grid filter inductor & $0.0017 \mathrm{H}$ \\
Switch frequency & $10 \mathrm{kHz}$ & Sample time & $0.1 \mathrm{~ms}$ \\
\hline
\end{tabular}

controller is used in this work. Then, the proposed ESObased PLL is used to obtain the grid voltage phase to synchronize the injected current with the grid voltage. Furthermore, the injected current control is achieved through three Proportional Resonant (PR) controllers upon the $a b c$ three-phase frame. More design details with respect to the control designs of $\mathrm{GcCs}$ can be found in the previous literatures [37-39]. Regarding the unbalanced conditions, various control strategies have been proposed before [40, 41]. In our tests, we use the positive sequence control strategy proposed in [40]. The PLL is used to detect the phase angle that follows the positive sequence of the grid voltage. For the ESO-based PLLs, we keep the same control parameters as configured in the simulation studies. The well-tuned parameters of the PI controller for the DC-link voltage and the PR controllers for grid-injected currents are provided in Table 3, and the detailed definitions of these parameters can be found in [9]. Since there is no difference between the synchronization phase angle during the unbalances and that during normal grid conditions, the same control parameters values are thus used for both balanced and unbalanced cases.

Figure 22 presents the closed-loop control performances of GcC equipped with ESO-based PLL/DPLL. Figure 22a shows the control performances under balanced grid. Testing results for unbalanced grid are provided in Fig. 22b. To highlight, we suppose that the unbalance is not affecting the phases but the magnitudes only. Then, the positive sequence is synchronized with the phase " $a$ " of the original threephase voltages. Therefore, the estimated phase of the positive sequence follows the original phase angle.

The test conditions are set as follows: a phase jump of $+20^{\circ}$ is manually added in Fig. 22a 1 and b1, a frequency step of $2 \mathrm{~Hz}$ happens in Fig. 22a2 and b2, and an magnitude drop of $0.2 V_{m}$ is considered in Fig. $22 \mathrm{a} 3$ and b3. First, the

Table 3 Control parameters of grid-connected converter

PI controller for DC-link voltage control: $k_{\mathrm{pv}}=0.12, k_{\mathrm{iv}}=8$

PR controller for grid current control: $k_{\mathrm{pr}}=0.15, k_{\mathrm{ir}}=10$, $\omega_{\text {rr }}=100 \pi$
Fig. 21 Schematic diagram of grid-connected converter with the commonly used control structure

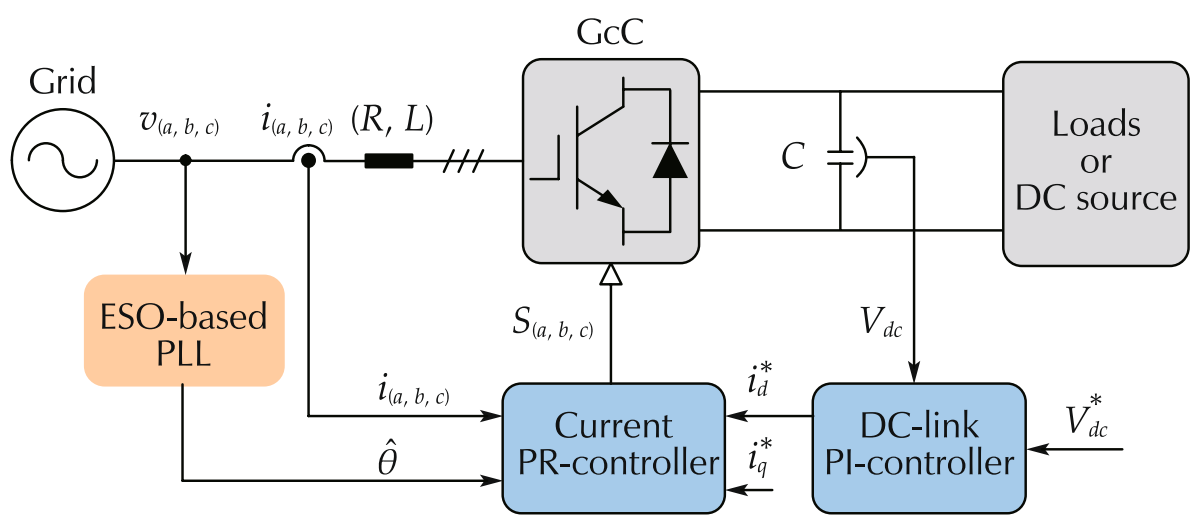




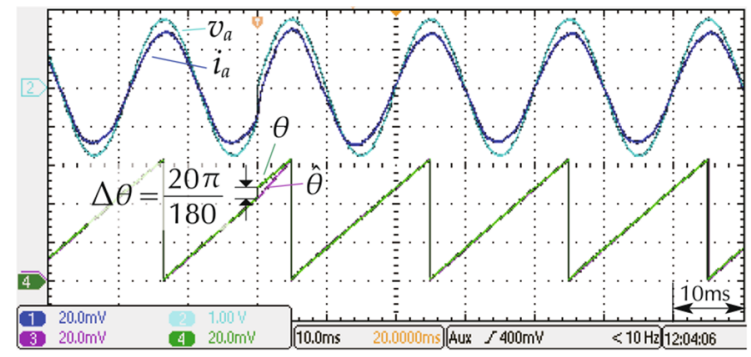

(a1)

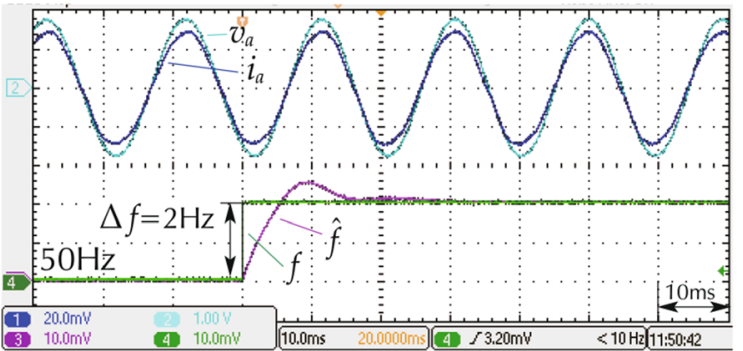

(a2)

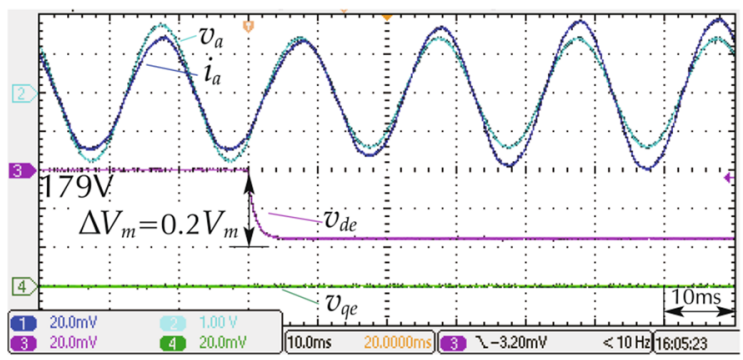

(a3)

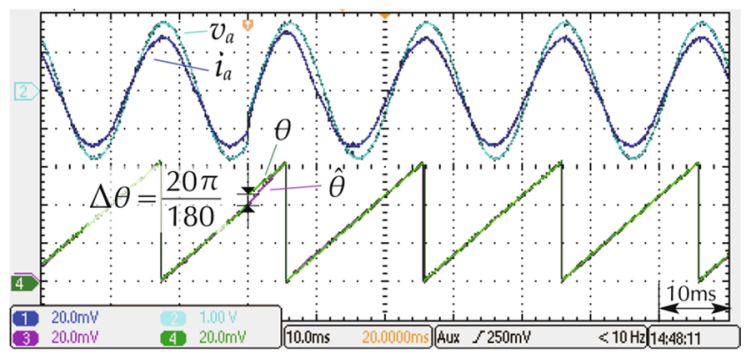

(b1)

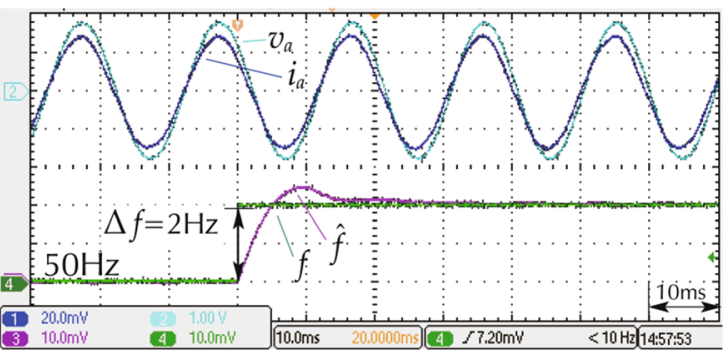

(b2)

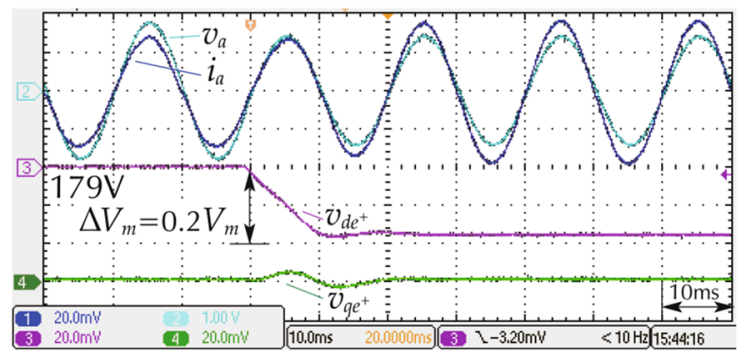

(b3)

Fig. 22 Grid-connected control performances with ESO-based PLL/DPLL under balanced and unbalanced grid conditions, the grid current of phase a $i_{a}(2 \mathrm{~A} / \mathrm{div})$, the grid voltage of phase a $v_{a}(100 \mathrm{~V} / \mathrm{div})$, for $\mathbf{a} 1$ and $\mathbf{b} 1$, a phase jump of $\Delta \theta=+20 \pi / 180 \mathrm{rad}$, the actual voltage phase $\theta$ ( $2 \mathrm{rad} / \mathrm{div})$, the estimated voltage phase $\hat{\theta}(2 \mathrm{rad} / \mathrm{div})$; for $\mathbf{a} 2$ and $\mathbf{b 2}$, a frequency step of $\Delta f=+2 \mathrm{~Hz}$, the actual grid frequency $f(1 \mathrm{~Hz} / \mathrm{div})$, the estimated grid frequency $\hat{f}(1 \mathrm{~Hz} / \mathrm{div})$; for $\mathbf{a} 3$ and $\mathbf{b 3}$, a voltage magnitude variation of $\Delta V_{m}=0.2 V_{m}$, the $d$-axis voltage $v_{d e}(20 \mathrm{~V} /$ div $)$, and the $q$-axis voltage $v_{q e}(20 \mathrm{~V} / \mathrm{div})$. (a1)-(a3) Balanced grid voltages. (b1)-(b3) Unbalanced grid voltages

ESO-based SRF-PLL/DPLL can correctly follow the phase, the frequency, and the voltage amplitude information. Then, the results indicate that the injected grid current $i_{a}$ synchronizes with the grid voltage $v_{a}$. Furthermore, the GcC's controls equipped with the ESO-based SRF-PLL/DPLL enable efficient performance regarding the control dynamics and the robustness in the presence of various disturbances.

\section{Conclusions}

This work is an extension for our previous work [8]. A linear ESO-based controller is designed as the LF for the SRFPLL. A tuning approach based on the well-tuned parameters of PI controller is provided, which results in a fair comparison with PI-type PLLs. Some conclusions can be drawn from the frequency domain analysis and the simulation results: the performances of the generated ESO-based controller are close to those of PI control at low frequency, while achieving a better ability of attenuating measurement noises. The phase margin decreases slightly, but remains acceptable. For the MAF-PLL with the in-loop filter, the equipped MAF itself could help attenuating the effects of high-frequency noises. Consequently, the advantage of ESO-based LF for its application to the MAF-PLL is not very significant. The PHIL experimental results suggest that the ESO-based PLLs can correctly obtain the phase, the frequency, and the voltage amplitude information. The obtained results show the effectiveness of ESO-based PLLs when applied to the GcC in the presence of various disturbances.

It is worth mentioning that this work has discussed a tuning approach based on the well-designed PI control. However, for the implementations of ESO-based control, it is not mandatory to tune them based on a PI controller. The linear 
ESO-based controller can be tuned simply by following the parameters selection guidelines provided in the previous works $[8,18,21]$.

Acknowledgements This paper was supported by G2elab, Grenoble INP, University Grenoble Alpes, France and School of Engineering, HES-SO, Valais, Switzerland.

Funding Open Access funding provided by Haute Ecole Specialisée de Suisse occidentale (HES-SO).

Open Access This article is licensed under a Creative Commons Attribution 4.0 International License, which permits use, sharing, adaptation, distribution and reproduction in any medium or format, as long as you give appropriate credit to the original author(s) and the source, provide a link to the Creative Commons licence, and indicate if changes were made. The images or other third party material in this article are included in the article's Creative Commons licence, unless indicated otherwise in a credit line to the material. If material is not included in the article's Creative Commons licence and your intended use is not permitted by statutory regulation or exceeds the permitted use, you will need to obtain permission directly from the copyright holder. To view a copy of this licence, visit http://creativecommons.org/licenses/by/4.0/.

\section{References}

1. Blaabjerg, F., Teodorescu, R., Liserre, M., \& Timbus, A. V. (2006). Overview of control and grid synchronization for distributed power generation systems. IEEE Transactions on Industrial Electronics, 53(5), 1398-1409.

2. Etxeberria-Otadui, I., Viscarret, U., Caballero, M., Rufer, A., \& Bacha, S. (2007). New optimized PWM VSC control structures and strategies under unbalanced voltage transients. IEEE Transactions on Industrial Electronics, 54(5), 2902-2914.

3. Santos Filho, R. M., Seixas, P. F., Cortizo, P. C., Torres, L. A. B., \& Souza, A. F. (2008). Comparison of three single-phase PLL algorithms for UPS applications. IEEE Transactions on Industrial Electronics, 55(8), 2923-2932.

4. Golestan, S., Guerrero, J. M., \& Vasquez, J. C. (2017a). Threephase PLLs: A review of recent advances. IEEE Transactions on Power Electronics, 32(3), 1894-1907.

5. Golestan, S., Guerrero, J. M., \& Vasquez, J. C. (2017). Singlephase PLLs: A review of recent advances. IEEE Transactions on Power Electronics, 32(12), 9013-9030.

6. Kaura, V., \& Blasko, V. (1996). Operation of a phase locked loop system under distorted utility conditions. In Proceedings of applied power electronics conference (pp. 703-708). San Jose, CA, USA.

7. Chung, S.-K. (2000). A phase tracking system for three phase utility interface inverters. IEEE Transactions on Power Electronics, 15(3), 431-438.

8. Guo, B., Bacha, S., Alamir, M., Boudinet, C., \& Mesnage, H. (2019) An enhanced phase-locked loop with extended state observer. In Proceedings of the 20th international symposium on power electronics (pp. 1-6). Novi Sad, Serbia.

9. Guo, B. (2019). Modelling and advanced controls of variable speed hydro-electric plants. Thèse. Grenoble, France: Université Grenoble Alpes. https://hal.archives-ouvertes.fr/tel-02296865. Accessed 25 Sept 2019.

10. Guo, B., Bacha, S., Alamir, M., Hably, A., \& Boudinet, C. (2020). Generalized integrator-extended state observer with applications to grid-connected converters in the presence of disturbances. IEEE Transactions on Control Systems Technology, 29(2), 744-755.

11. Geng, H., Liu, L., \& Li, R. (2018). Synchronization and reactive current support of PMSG-based wind farm during severe grid fault. IEEE Transactions on Sustainable Energy, 9(4), 1596-1604.

12. Lai, M., Nakano, M., \& Hsieh, G. (1996). Application of fuzzy logic in the phase-locked loop speed control of induction motor drive. IEEE Transactions on Industrial Electronics, 43(6), 630-639.

13. Sinha, R. K., \& Sensarma, P. (2011). A pre-filter based PLL for three-phase grid connected applications. Electric Power Systems Research, 81(1), 129-137.

14. Choi, H.-J., Song, S.-H., Jeong, S.-G., Choi, J.-Y., \& Choy, I. (2011). Enhanced dynamic response of SRF-PLL system for high dynamic performance during voltage disturbance. Journal of Power Electronics, 11(3), 369-374.

15. Thacker, T., Boroyevich, D., Burgos, R., \& Wang, F. (2011). Phase-locked loop noise reduction via phase detector implementation for single-phase systems. IEEE Transactions on Industrial Electronics, 58(6), 2482-2490.

16. Ghartemani, M. K., Khajehoddin, S. A., Jain, P. K., \& Bakhshai, A. (2012). Problems of startup and phase jumps in PLL systems. IEEE Transactions on Power Electronics, 27(4), 1830-1838.

17. Han, J. (2009). From PID to active disturbance rejection control. IEEE Transactions on Industrial Electronics, 56(3), 900-906.

18. Gao, Z. (2006). Scaling and bandwidth-parameterization based controller tuning. In Proceedings of the American control conference (pp. 4989-4996). Denver, CO, USA

19. Madoski, R., \& Herman, P., (2015). Survey on methods of increasing the efficiency of extended state disturbance observers. ISA Transactions, 56, 18-27.

20. Jin, H., Chen, Y., \& Lan, W. (2019). Replacing PI control with first-order linear ADRC. In IEEE 8th data driven control and learning systems conference (pp. 1097-1101). Dali, China.

21. Guo, B., Bacha, S., Alamir, M., Mohamed, A., \& Boudinet, C. (2019). LADRC applied to variable speed micro-hydro plants: experimental validation. Control Engineering Practice, 85, 290-298.

22. Lu, J., Golestan, S., Savaghebi, M., Vasquez, J. C., Guerrero, J. M., \& Marzabal, A. (2018). An enhanced state observer for DC-link voltage control of three-phase AC/DC converters. IEEE Transactions on Power Electronics, 33(2), 936-942.

23. Zhou, Z., Ben Elghali, S., Benbouzid, M., Amirat, Y., Elbouchikhi, E., \& Feld, G. (2019) Control strategies for tidal stream turbine systems - a comparative study of ADRC, PI, and highorder sliding mode controls. In Proceedings of the 45th annual conference of the IEEE Industrial Electronics Society (pp. 6981-6986). Lisbon, Portugal.

24. Araki, M., \& Taguchi, H. (2003). Two-degree-of-freedom PID controllers. International Journal of Control, Automation, and Systems, 1(4), 401-411.

25. Miklosovic, R., Gao,Z. (2004). A robust two-degree-of-freedom control design technique and its practical application. In Conference record of the IEEE industry applications conference: covering theory to practice (pp. 1495-1502). Seattle, WA, USA.

26. Sun, B., \& Gao, Z. (2005). A DSP-based active disturbance rejection control design for a 1-kW H-bridge DC-DC power converter. IEEE Transactions on Industrial Electronics, 52(5), 1271-1277.

27. Rodriguez, P., Pou, J., Bergas, J., Candela, J. I., Burgos, R. P., \& Boroyevich, D. (2007). Decoupled double synchronous reference frame PLL for power converters control. IEEE Transactions on Power Electronics, 22(2), 584-592.

28. Golestan, S., Ramezani, M., Guerrero, J. M., Freijedo, F. D., \& Monfared, M. (2014). Moving average filter based phase-locked loops: Performance analysis and design guidelines. IEEE Transactions on Power Electronics, 29(6), 2750-2763. 
29. Guo, B., Bacha, S., \& Alamir, M. (2017) A review on ADRC based PMSM control designs. In Proceedings of the 43rd annual conference of the IEEE Industrial Electronics Society (pp. 17471753). Beijing, China.

30. Yoo, D., Yau, S. S.-T., \& Gao, Z. (2006). On convergence of the linear extended state observer. In IEEE international conference on control applications (pp. 1645-1650). Munich, Germany.

31. Tatsumi, J., \& Gao, Z. (2013). On the enhanced ADRC design with a low observer bandwidth. In Proceedings of the 32nd Chinese control conference (pp. 297-302). Xi'an, China.

32. Safonov, M., Laub, A., \& Hartmann, G. (1981). Feedback properties of multivariable systems: The role and use of the return difference matrix. IEEE Transactions on Automatic Control, 26(1), 47-65.

33. Tian, G., \& Gao, Z. (2007). Frequency response analysis of active disturbance rejection based control system. In IEEE international conference on control applications (pp. 1595-1599). Singapore.

34. Cao, Y., Zhao, Q., Ye, Y., \& Xiong, Y. (2020). ADRC-based current control for grid-tied inverters: Design, analysis, and verification. IEEE Transactions on Industrial Electronics, 67(10), 8428-8437.

35. Ocnasu, D., Gombert, C., Bacha, S., Roye, D., Blache, F., \& Mekhtoub, S. (2008). Real-time hybrid facility for the study of distributed power generation systems. Revue des Energies Renouvelables, 11(3), 343-356.

36. Guo, B., Mohamed, A., Bacha, S., Alamir, M., Boudinet, C., \& Pouget, J. (2020). Reduced-scale models of variable speed hydro-electric plants for power hardware-in-the-loop real-time simulations. Energies, 13(21), 5764. https://doi.org/10.3390/ en13215764.

37. Guo, B., Bacha, S., Alamir, M., \& Iman-Eini, H. (2019) A robust LESO-based DC-link voltage controller for variable speed hydroelectric plants. In IEEE international conference on industrial technology (pp. 361-366). Melbourne, Australia.

38. Zmood, D. N., \& Holmes, D. G. (2003). Stationary frame current regulation of PWM inverters with zero steady-state error. IEEE Transactions on Power Electronics, 18(3), 814-822.

39. Guo, B., Mohamed, A., Bacha, S., \& Alamir, M. (2018). Variable speed micro-hydro power plant: Modelling, losses analysis, and experiment validation. In IEEE international conference on industrial technology (pp. 1079-1084). Lyon, France.

40. Alepuz, S., Busquets-Monge, S., Bordonau, J., Martinez-Velasco, J. A., Silva, C. A., Pontt, J., et al. (2009). Control strategies based on symmetrical components for grid-connected converters under voltage dips. IEEE Transactions on Industrial Electronics, 56(6), 2162-2173.

41. Li, Z., Zhao, R., Xin, Z., Guerrero, J. M., Savaghebi, M., \& Li, P. (2016). Inrush transient current analysis and suppression of photovoltaic grid-connected inverters during voltage sag. In IEEE applied power electronics conference and exposition (pp. 36973703). Long Beach, CA, USA.

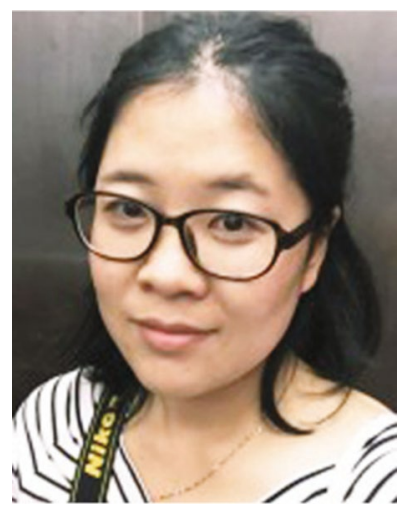

Baoling Guo received the B.Sc. and M.Sc. degrees from the China University of Petroleum, Qingdao, China, in 2012 and 2014, respectively, and the M.Sc. degree from the Grenoble Institute of Technology (INPG), Grenoble, France, in 2015, and the Ph.D. degree from Grenoble Electrical Engineering Laboratory (G2Elab), University Grenoble Alpes, Grenoble, France, in 2019. Her main research interests include variable speed hydropower generation, power electronics system modelling and control, and renewable energy integration.

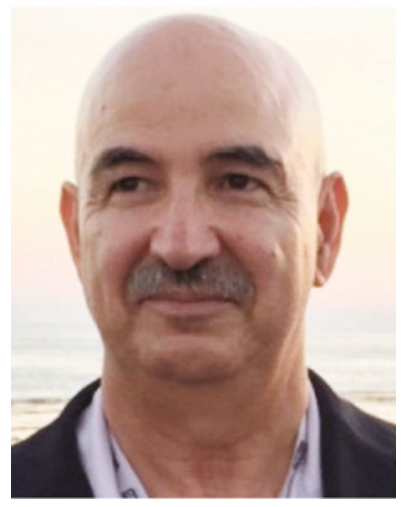

Seddik Bacha received the B.Sc. and M.Sc. degrees from the Ecole Nationale Polytechnique d'Alger, Algiers, Algeria, in 1982 and 1990, respectively, and the $\mathrm{Ph} . \mathrm{D}$. degree from the Grenoble Institute of Technology (INPG), Grenoble, France, in 1993. In 1990, he joined the Laboratoire d'Electrotechnique de Grenoble. From 2001 to 2012, he was the Manager of the Power Systems Group, Grenoble Electrical Engineering Laboratory, INPG. He is currently a Professor with Univ. Grenoble Alpes.

His research interests include power electronics system modelling and control, power quality, and renewable energy integration.

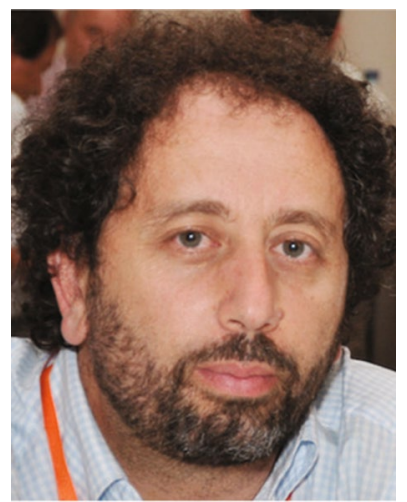

Mazen Alamir graduated in mechanics in Grenoble, France, in 1990, and in aeronautics in Toulouse, France, in 1992. He received the $\mathrm{Ph} . \mathrm{D}$. degree in nonlinear model predictive control from the Grenoble Institute of Technology (Grenoble INP), Grenoble, France, in 1995. He has served as the Head of the Systems and Complexity Research Group, Control Systems Department, Gipsa-Lab, Grenoble. Since 1996, he has been a CNRS Research Associate with the Control Systems Department, Gipsa-Lab. His main research topics are model predictive control, receding horizon observers, nonlinear hybrid systems, signature-based diagnosis, optimal cancer treatment, and industrial applications. Dr. Alamir is also an Associate Editor of the IEEE Transactions on Automatic Control (IEEE-TAC). His home page is www.mazenalamir.fr.

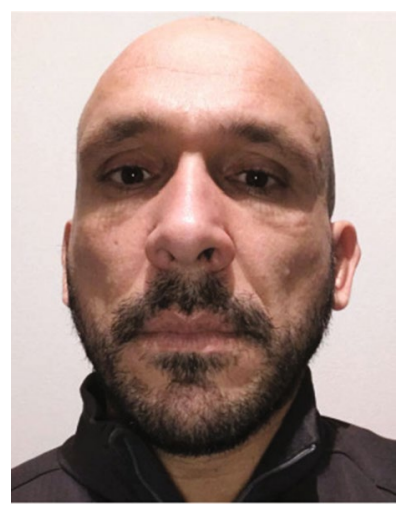

Julien Pouget received the Ph.D. degree in electrical engineering from the University of FrancheComté, Belfort, France, in 2009, and the M.Sc. degree in control of electrical systems from the Institut National Polytechnique de Toulouse, Toulouse, France, in 2005. For 3 years, he worked on the optimal design of electrical railway traction motor systems within the Research Department of ALSTOM Transport. Since 2009, he has been a Researcher with the Innovation and Research Department, French National Railway Company. His research interests include the optimal design, modeling, control, and energy management of railway hybrid energy systems (rolling stock, railway smart-grid, and electrical railway networks). After 12 years in industrial research, in 2018, he joined the smart-grid applied research team at HES-SO, Valais Wallis. 